\title{
COMBATE A INCÊNDIOS EM EDIFICAÇÕES COM GERADORES DE ENERGIA SOLAR FOTOVOLTAICA CONECTADOS À REDE: OBSERVAÇÕES INICIAIS
}

\author{
Elison Eduardo Jardim Bierhals ${ }^{1}$ \\ Claudinéia Machado Brazil ${ }^{2}$
}

\section{RESUMO}

A crescente popularização da utilização da energia fotovoltaica e devido as suas características elétricas peculiares, tornou imprescindível estudos relacionados ao combate e prevenção de incêndios em edificações com equipamentos de energia solar fotovoltaica que possam subsidiar as equipes de bombeiros/brigadistas. Um efeito da falta de informação sobre o assunto é o desenvolvimento de receio por parte dos bombeiros/brigadistas ao atenderem algum incêndio em módulos fotovoltaicos, isso pode gerar uma certa inércia por parte destes profissionais potencializando o prejuízo humano e material. Cabe salientar que por ter uma regulação relativamente recente, e uma popularização mais recente ainda, a mini e microgeração distribuída carece de estudos e normas específicas e atuais que possam atender de forma satisfatória e segura a esta nova tendência da geração de energia. O presente estudo concluiu que até que seja incorporado ao gerador fotovoltaico dispositivos eletrônicos que eliminem o risco de choque elétrico, em razão da corrente contínua existente entre os módulos e o inversor, os bombeiros/brigadistas deverão utilizar as técnicas seguras já existentes de combate a equipamentos energizados.

Palavras-chave: Combate a Incêndios. Energia Fotovoltaica. Eletricidade.

\footnotetext{
${ }^{1}$ Bombeiro Militar do Rio Grande do Sul. Engenheiro de Energia pela Universidade Estadual do Rio Grande do Sul. Especialista em Gestão de Riscos e Desastres Naturais.

${ }^{2}$ Meteorologista - Universidade Federal de Pelotas. Mestre em Sensoriamento Remoto Universidade Federal do Rio Grande do Sul. Doutora em Recursos Hídricos - Universidade Federal do Rio Grande do Sul. Engenheira de Energia - Universidade Estadual do Rio Grande do Sul.
} 


\title{
FIRE FIGHTING IN BUILDINGS WITH PHOTOVOLTAIC SOLAR ENERGY GENERATORS CONNECTED TO THE NETWORK: INITIAL COMMENTS
}

\begin{abstract}
The increasing popularization of the use of photovoltaic energy and due to its peculiar electrical characteristics, made studies related to the combat and prevention of fires in buildings with photovoltaic solar energy equipment that can subsidize the teams of firefighters/brigadiers essential. An effect of the lack of information on the subject is the development of fear on the part of firefighters / brigadiers when attending a fire in photovoltaic modules, this can generate a certain inertia on the part of these professionals, potentiating human and material damage. It should be noted that due to its relatively recent regulation, and even more recent popularization, the mini and distributed microgeneration lacks specific and current studies and standards that can satisfactorily and safely meet this new trend in energy generation. The present study concluded that until electronic devices are incorporated into the photovoltaic generator that eliminate the risk of electric shock, due to the direct current existing between the modules and the inverter, the firefighters/brigade must use the already existing safe techniques to combat equipment energized.
\end{abstract}

Key words: Fire Fighting. Photovoltaic Energy. Electricity.

Artigo Recebido em 19/11/2020 e Aceito em 25/05/2021 


\section{INTRODUÇÃO}

Com a crescente popularização e devido as suas características elétricas peculiares, tornam-se imprescindíveis estudos relacionados ao combate e prevenção de incêndios em edificações com equipamentos de energia solar fotovoltaica. Podemos pensar em dois paradigmas importantes sobre a necessidade de aprofundar e disseminar o conhecimento nesta área com crescimento tão importante: Um a preservação da vida e outro a preservação do patrimônio.

Segundo a NR10 quando ocorre um sinistro do tipo incêndio em uma edificação com energia elétrica, ou até mesmo na própria rede elétrica de distribuição ou transmissão de energia, a primeira medida de proteção coletiva que deve ser adotada é a desenergização do ramal afetado, para que aja segurança aos bombeiros na operação de combate ao fogo, contudo essa manobra pode ser insuficiente quando o incêndio for em instalações equipadas com geradores fotovoltaicos, pois aparte do circuito de corrente contínua, segue energizada, ou seja, existindo irradiação sobre os painéis esse tipo de equipamento continua gerando energia mesmo quando a rede está desligada, colocando em risco a vida de bombeiros/brigadistas que por ventura venham a atender essa ocorrência.

Um outro efeito da falta de informação sobre 0 assunto é 0 desenvolvimento de receio por parte dos bombeiros/brigadistas ao atenderem algum incêndio em módulos fotovoltaicos, isso pode gerar uma certa inércia por parte destes profissionais potencializando o prejuízo humano e material. 


\section{MATERIAIS E MÉTODOS}

\section{Mini e Microgeração Distribuída}

A publicação da Resolução Normativa № 482, de 17 de abril de 2012 da AGÊNCIA NACIONAL DE ENERGIA ELÉTRICA (ANEEL) estabelece as condições gerais para o acesso de microgeração e minigeração distribuída aos sistemas de distribuição de energia elétrica, pode ser considerada como um marco na popularização da energia solar fotovoltaica (ESF) pois foi com o advento deste dispositivo legal que o mercado e os consumidores tiveram incentivo para mini/microgeração distribuída.

Microgeração distribuída: central geradora de energia elétrica, com potência instalada menor ou igual a $75 \mathrm{~kW}$ e que utilize cogeração qualificada, conforme regulamentação da ANEEL, ou fontes renováveis de energia elétrica, conectada na rede de distribuição por meio de instalações de unidades consumidoras, ANEEL (2015).

Minigeração distribuída: central geradora de energia elétrica, com potência instalada superior a $75 \mathrm{~kW}$ e menor ou igual a $5 \mathrm{MW}$ e que utilize cogeração qualificada, conforme regulamentação da ANEEL, ou fontes renováveis de energia elétrica, conectada na rede de distribuição por meio de instalações de unidades consumidoras, ANEEL (2015).

\section{Norma Regulamentadora 10 e 23 (NR10 e NR 23)}

A NR 10 tem como finalidade orientar os trabalhadores sobre os riscos que estão submetidos como os cuidados que devem ser tomados para trabalhar com segurança e responsabilidade (MINISTÉRIO DO TRABALHO, 2019).

Conforme item 10.1.1 da NR - 10, diz:

10.1.1 Esta Norma Regulamentadora - NR estabelece os requisitos e condições mínimas objetivando a implementação de medidas de controle e sistemas preventivos, de forma a garantir a segurança e a saúde dos trabalhadores que, direta ou indiretamente, interajam em 
instalações elétricas e serviços com eletricidade (MINISTÉRIO DO TRABALHO, 2019).

A referida norma é mais específica no seu item 10.9.1 onde afirma que as instalações em que houver equipamentos elétricos instalados deverão possuir proteção contra incêndio de acordo com o que especifica a NR 23 e qual o tipo de agente extintor deve ser empregado no combate a incêndios em materiais energizados, reforçando que a água só poderá ser utilizada de forma pulverizada.

...10.9.1 As áreas onde houver instalações ou equipamentos elétricos devem ser dotadas de proteção contra incêndio e explosão, conforme dispõe a NR 23 - Proteção Contra Incêndios...

...Classe $\mathrm{C}$ - quando ocorrem em equipamentos elétricos energizados como motores, transformadores, quadros de distribuição, fios etc... ...23.10.4 A água nunca será empregada nos fogos da Classe $\mathrm{C}$, salvo quando se tratar de água pulverizada;

\section{Instrução Técnica no 21/2018 (IT 21)}

A referida Instrução Técnica do Corpo de Bombeiros da Polícia Militar do Estado de São Paulo, versa sobre proteção de incêndios por meio de extintores portáteis ou carroçados como forma de combate a princípios de incêndio, em seu item 5.2.1.12 faz referência aos riscos específicos que devem ser protegidos por extintores de incêndio, independente da proteção geral da edificação ou área de risco.

Ainda neste mesmo item a IT 21 apresenta um rol exemplificativo que é aquele que estabelece apenas alguns itens de uma lista diferentemente do rol taxativo, que estabelece uma lista determinada, não dando margem a interpretações extensivas.

Estabelecer critérios para proteção contra incêndio em edificações e áreas de risco por meio de extintores de incêndio (portáteis ou sobrerrodas), para o combate a princípios de incêndios.... 
5.2.1.12 Riscos específicos devem ser protegidos por extintores de incêndio, independente da proteção geral da edificação ou área de risco, tais como: ... c. casa de força elétrica; ... i. quadros elétricos... j. transformadores... (Brasil, 2018).

\section{RESULTADOS}

\section{Técnicas Ineficazes para combate a incêndio em Edificações com ESF}

\section{Desligamento do Inversor}

Segundo a IEC 62109-2 (2011), as funções de desligamento em inversores tradicionais apenas cortam o fluxo de corrente entre os módulos e o inversor, enquanto a tensão permanece perigosamente alta nos arranjos dos módulos.

Como o recomendável é sempre desligar primeiramente o disjuntor geral da residência, o inversor já vai se desligar automaticamente, então não tem motivo tentar seccioná-lo na string box.

\section{Chaves Seccionadoras de Corrente Contínua}

As chaves seccionadoras são consideradas indispensáveis ao sistema de energia elétrica pois possibilitam o isolamento físico entre o inversor e a rede elétrica de distribuição, desta forma, asseguram o trabalho seguro para os funcionários das distribuidoras de energia que realizam manutenção nas linhas de distribuição, Severo (2008).

Porém as chaves seccionadoras CC localizados no gabinete do inversor tradicional ou na string box, não podem desconectar a tensão dos módulos. Arranjos fotovoltaicos em telhados que são desconectados apenas por chaves seccionadoras apenas interrompem o fluxo de corrente do telhado para o inversor, os módulos sobre o telhado, seus cabos até o inversor permanecem energizados enquanto a luz solar estiver incidindo sobre os painéis. 


\section{Energia no Gerador Fotovoltaico}

Nos sistemas interligados à rede elétrica de distribuição, os geradores fotovoltaicos podem ser dimensionados para atender parte ou toda demanda da edificação. Essa produção de energia ocorre em corrente contínua (CC) e a utilização de eletricidade é feita em corrente alternada (CA). Assim, é necessário um inversor que irá transformar $\mathrm{CC}$ em CA

Figura 1 - Sistema fotovoltaico conectado à rede

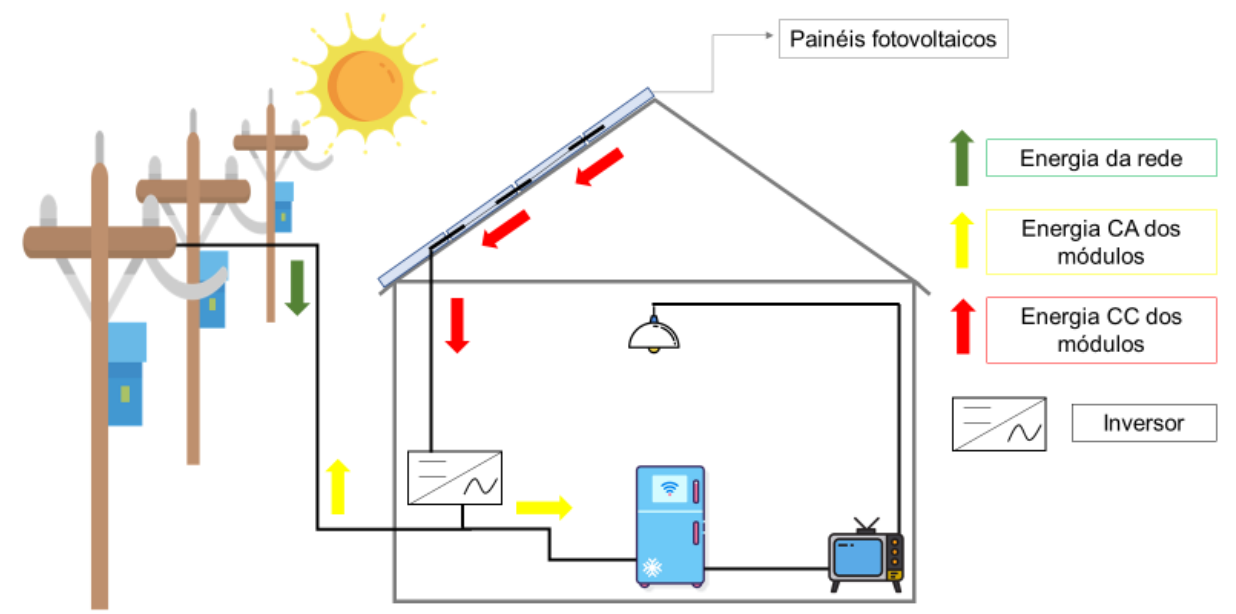

Fonte: O Autor

Nestes sistemas, pode-se utilizar tanto a energia fotovoltaica como a convencional da distribuidora (Figura 10). Nesse tipo de conexão, não há a necessidade de banco de baterias, pois quando se tem um consumo elétrico maior que a eletricidade produzida pelos módulos fotovoltaicos, a distribuidora irá fornecer a energia necessária para o funcionamento da edificação e, quando o consumo elétrico for baixo ou os módulos estiverem produzindo eletricidade acima do que está sendo consumido pela edificação, o excesso de 
energia elétrica é injetado na rede de distribuição da concessionária (ZILLES,2016).

Uma dúvida comum sobre energia fotovoltaica é: instalar um sistema de energia solar fotovoltaico on grid e faltar energia na concessionária eu terei ainda energia elétrica? A resposta é não, pois quando falta energia na rede de distribuição, por uma questão de segurança, o inversor se desliga também interrompendo assim a corrente elétrica que flui para a residência e/ou para a rede elétrica.

Entretanto, mesmo com a energia da rede sendo interrompida e o inversor estando desligado, durante o dia e enquanto a luz solar estiver incidindo sobre os painéis existirá tensão elétrica entre os módulos e 0 inversor, como representado pela seta vermelha da Figura 11, isso acontece porque não existe botão de desliga nos módulos e isso pode ser fatal para o bombeiro/brigadista que não utilize técnicas adequadas para combater um eventual incêndio com estes equipamentos.

Figura 2 - Sistema fotovoltaico conectado à rede sem energia

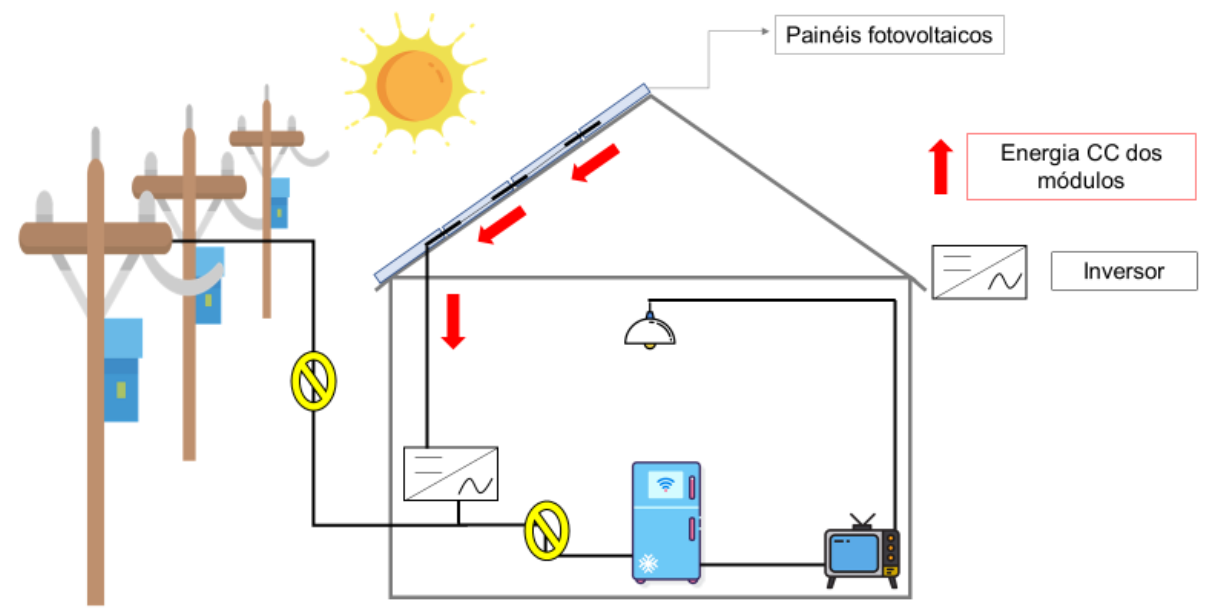

Fonte: O Autor 
Técnica de Combate a incêndios em equipamentos energizados

De acordo com Electrical Safety (2013) a água pode ser aplicada com segurança, conhecendo a tensão envolvida e cumprindo estritamente com 0 seguinte distâncias mínimas, pressões, tamanho do bico e padrão de pulverização Tabela 1.

Uma regra fácil de lembrar é ficar para trás 10 metros a menos que tenha certeza de que a tensão é menos de 750 volts.

Tabela 1: Distâncias seguras para usar água em equipamentos energizados.

Tensão do equipamento Distâncias Mínimas a 700 Kpa no Esguicho

$\begin{array}{ll}\text { Volts } & \text { Neblina } \\ 0 \text { a } 750 & 1,5 \text { metros } \\ 751 \text { a } 15000 & 4 \text { metros } \\ 15001 \text { a } 500000 & 7 \text { metros }\end{array}$

Fonte: Adaptado Electrical Safety. Handbook for Emergency Responders 
Figura 3 - Combate a incêndios em equipamentos energizados

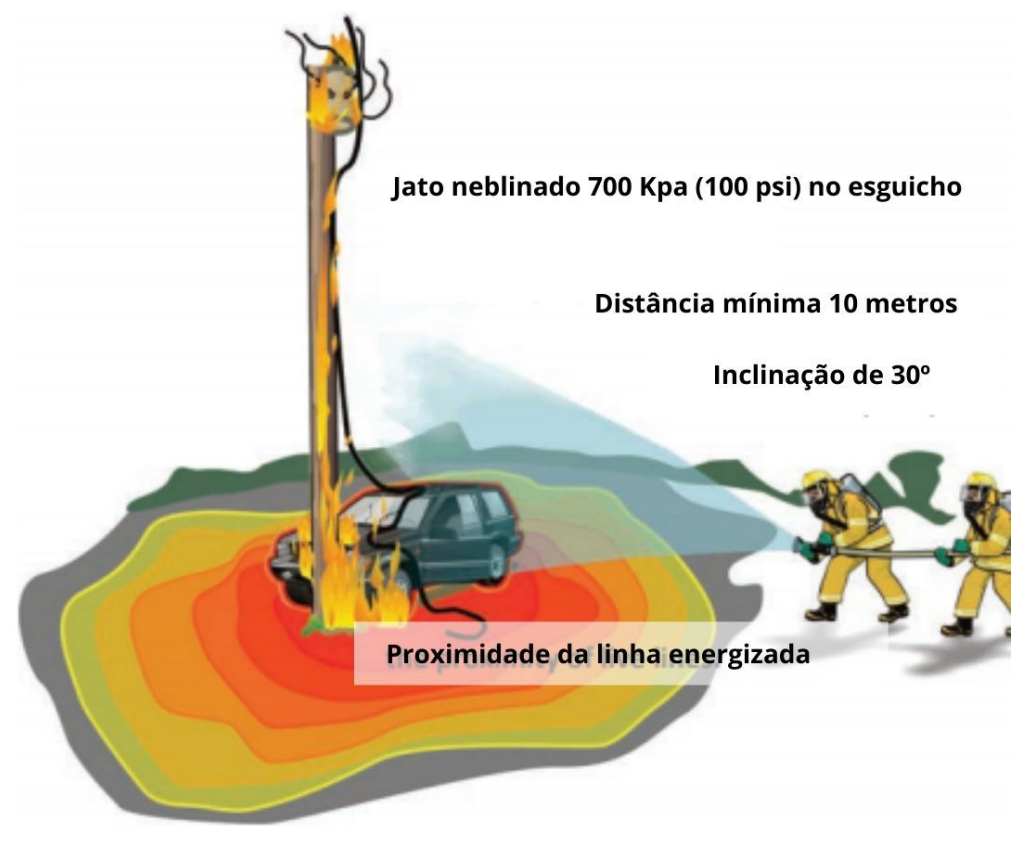

Fonte: Adaptado Electrical Safety (2013).

Ao deparar-se com uma ocorrência envolvendo instalações com painéis fotovoltaicos, primeiramente o bombeiro deve desligar a energia geral do local, o que vai ocasionar o desligamento do inversor, cessando assim o envio de eletricidade para a rede de distribuição e a chegada de eletricidade nos condutores da residência (CBMRS 2020), entretanto cabe reforçar que somente essa manobra é insuficiente quando o incêndio for em instalações equipadas com geradores fotovoltaicos, pois o circuito de corrente contínua, segue energizado, ou seja, existindo irradiação sobre os módulos fotovoltaicos o sistema continua gerando energia mesmo quando a rede está desligada, colocando em risco a vida de bombeiros/brigadistas que por ventura venham a atender essa ocorrência e não tenham conhecimento desta característica peculiar deste tipo de equipamento. 
De acordo com o National Renewable Energy Lab (NREL, 2017) no caso de incêndios, os sistemas fotovoltaicos devem ser tratados da mesma forma que equipamentos elétricos energizados, porém com uma peculiaridade importante, que é uma incapacidade da interrupção desta energia enquanto os painéis estiverem iluminados pela luz solar.

O jato compacto (Figura 9) deve ser evitado, assim como nas demais situações já consolidadas de combate a incêndio em equipamentos energizados, pois da forma como é encontrada na natureza ou como sai em nossas torneiras e hidrantes, a água tem na sua composição elementos que a tornam condutora de eletricidade (CBMGO, 2016).

Figura 4 - Jato Compacto (a) Jato Neblinado (b)

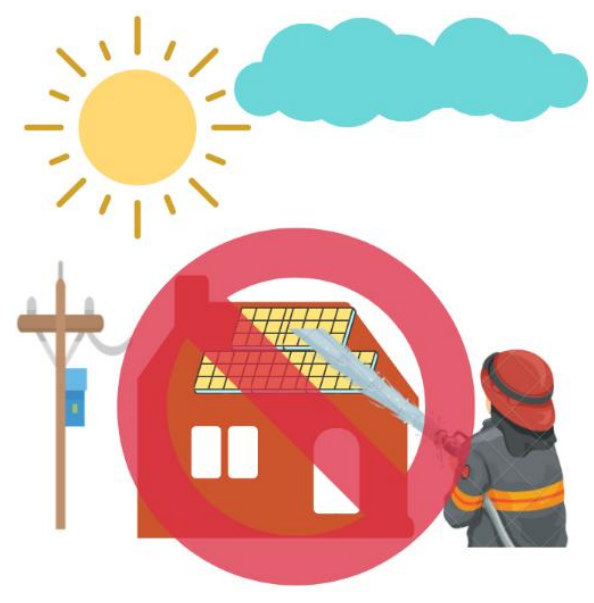

a)

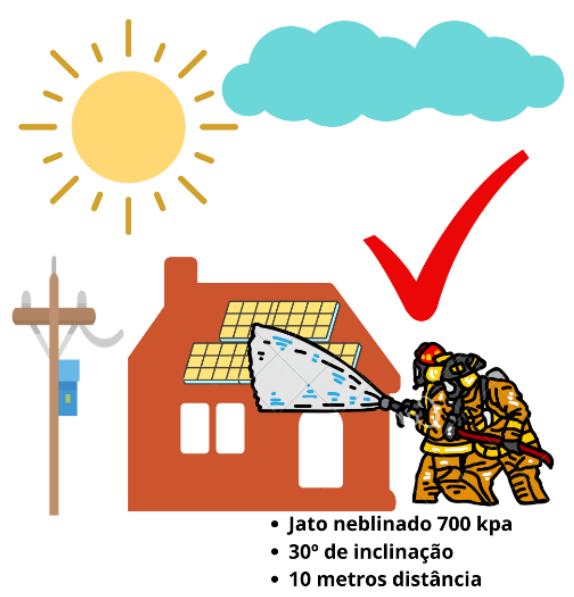

b)

Fonte: O autor

\section{CONCLUSÕES}

Um problema que surge silenciosamente e que pode potencializar os estragos causados por incêndios onde exista a presença de sistemas fotovoltaicos, é a eventual relutância dos bombeiros em combater incêndios em edificações com módulos fotovoltaicos no telhado. Essa relutância não é por acaso, pois mesmo que o inversor possa ser localizado e desligado, e o 
disjuntor geral da instalação for desligado, inclusive se a rede de distribuição deixar de entregar eletricidade, enquanto o Sol estiver brilhando os módulos estarão gerando eletricidade e com muitos condutores energizados.

Além do risco elétrico, os sistemas fotovoltaicos podem ocupar uma área considerável do telhado, representando um obstáculo físico extra para os bombeiros e demais equipes de combate e prevenção contra incêndios, assim como um peso excedente para a estrutura da edificação em via de colapso devido o comprometimento resultante da alta temperatura do incêndio.

Aos bombeiros/brigadistas devem ser fornecidos treinamento especial para que eles entendam os sistemas fotovoltaicos e possam lidar efetivamente com incêndios em instalações com este tipo de equipamento, devem ser informados de que mesmo depois desconectando o sistema fotovoltaico da rede de energia, os arranjos podem continuar a gerar tensões de CC perigosamente altas.

Até que seja incorporado ao gerador fotovoltaico dispositivos eletrônicos que eliminem o risco de choque elétrico em razão da corrente contínua existente entre os módulos e o inversor, os bombeiros/brigadistas deverão utilizar as técnicas seguras já existentes de combate a equipamentos energizados.

Uma medida que pode surtir efeito benéfico do ponto de vista da segurança e combate contra princípios de incêndio é a obrigatoriedade da instalação de extintor de incêndio do tipo $A B C$ em residências e/ou edificações que possuam geradores fotovoltaicos, semelhante ao que ocorre em quadros elétricos, casas de força e transformadores, desta forma pequenos focos de incêndio destas instalações poderiam ser prontamente extintos diminuindo assim o risco de um incêndio de grandes proporções nestes locais. 


\section{REFERÊNCIAS}

ASSOCIAÇÃO BRASILEIRA DE NORMAS TÉCNICAS (ABNT). NBR 5410: Instalações elétricas de baixa tensão. Rio de janeiro Paulo, 2004

\section{NBR 5419 Proteção de estruturas contra descargas} atmosféricas. Rio de Janeiro 2011.

ANEEL.Resolução Normativa ํㅡ 482/2012 de 17 de abril de 2012. 2012 B. Disponível em <www.aneel.gov.br. Acesso em 21 de setembro de 2020>

BRASIL, Ministério de Minas e Energia. Balanço Energético Nacional 2020 ano base 2019. Empresa de Pesquisa Energética (EPE), Brasília, DF. Disponível em. $\quad<\quad$ https://www.epe.gov.br/pt/publicacoes-dadosabertos/publicacoes/balanco-energetico-nacional-2020 >

Ministério do Trabalho e do Emprego. NR-06 - EQUIPAMENTO DE PROTEÇÃO INDIVIDUAL - EPI. Aprovada pela Portaria MTb n.ํ 3.214, de 08 de junho de 1978.

NR-10 - Segurança em Instalações e Serviços em Eletricidade. . Aprovada pela portaria $n^{\circ} 598$, de 07 de dezembro de 2004, publicada no D.O.U. em 8 de dezembro de 2004.Brasil, 2004.

. Lei n. 5.194, de 24 de dezembro de 1966. Regula o exercício das profissões de Engenheiro, Arquiteto e Engenheiro- Agrônomo, e dá outras providências. Diário Oficial da União, Brasília, DF, 27 dez. 1966. Disponível em:

Lei n. 6.496, de 07 de dezembro de 1977. Institui a "Anotação de Responsabilidade Técnica" na prestação de serviços de Engenharia, de Arquitetura e Agronomia; autoriza a criação, pelo Conselho Federal de Engenharia, Arquitetura e Agronomia - CONFEA, de uma Mútua de Assistência Profissional, e dá outras providências. Diário Oficial da União, Brasília, DF, 09 dez. 1977. Disponível em: .

. Estado de São Paulo. Polícia Militar. Corpo de Bombeiros. IT 21: Sistema de proteção por extintores de incêndio. São Paulo, 2018.

BRENTANO, Telmo. Instalações hidráulicas de combate a incêndios nas edificações. EDIPUCRS, 2004. 
BRONZATTI, F. L.; IAROZINSKI NETO, A. Matrizes energéticas no Brasil: cenário 2010-2030. In: ENCONTRO NACIONAL DE ENGENHARIA DE PRODUÇÃO, p.28., 2008, Rio de Janeiro, 2008.

CASTRO, Rui MG. Introdução à energia fotovoltaica. DEEC/Seção de Energia Lisboa: Universidade Técnica de Lisboa. Instituto Superior Técnico, 2002.

CORDOVA, Adam et al. Rapid Shutdown with Panel Level Electronics-A suitable safety measure?. In: 2017 IEEE 44th Photovoltaic Specialist Conference (PVSC). IEEE, 2017. p. 1965-1967.

Corpo de Bombeiros Militar do Estado de Goiás. Goiânia-GO, 2016.

Corpo de Bombeiros Militar do Estado de Rio Grande do Sul. ELETRICIDADE APLICADA À FUNÇÃO BOMBEIRO MILITAR Porto AlegreRS, 2020.

GONÇALVES, Edwar Abreu; CRUZ, VMCDA. Segurança e medicina do trabalho. São Paulo: LTr, 1996.

INTERNATIONAL ELECTROTECHNICAL COMMISION. Safety of power converters for use in photovoltaic power systems. Part 2 - Particular requirements for inverters. IEC 62109-2, 2011.

OLIVEIRA, GIDEAO et al. BOMBEIROS MILITAR DO ESTADO DE GOIAS. Especialização Em Gerenciamento Segurança Pública De Aperfeiçoamento De Oficiais. 2015.

Photovoltaics and Firefighters' Operations: Best Practices in Selected Countries. National Renewable Energy Lab. (NREL), Golden, CO (United States), 2017.

RIO GRANDE DO SUL. Lei complementar no 14376, de 26 de dezembro de 2013. Estabelece normas sobre Segurança, Prevenção e Proteção contra Incêndios nas edificações e áreas de risco. Diário Oficial do Estado do Rio Grande do Sul, Porto Alegre, 2013.

Decreto ํㅡ 53.280, de $1^{\circ}$ de novembro de 2016. Altera o Decreto $\mathrm{n}^{-}$51.803, de 10 de setembro de 2014, que regulamenta a Lei Complementar ํㅜ 14.376, de 26 de dezembro de 2013, e alterações, que estabelece normas sobre segurança, prevenção e proteção contra incêndio nas edificações e áreas de risco de incêndio no Estado do Rio Grande do Sul.

SEVERO, Leonardo et al. Estudo e implementaçao de métodos de proteçao de anti-ilhamento aplicados a sistemas fotovoltaicos. 2011. 
ZILLES, Roberto et al. Sistemas fotovoltaicos conectados à rede elétrica. Oficina de Textos, 2016. 